\title{
The color removal and fate of organic pollutants in a pilot- scale MBR-NF combined process treating textile wastewater with high water recovery
}

\author{
Kun Li, Chao Jiang, Jianxing Wang and Yuansong Wei
}

\begin{abstract}
A combination of membrane bioreactor (MBR) and nanofiltration (NF) was tested at pilot-scale treating textile wastewater from the wastewater treatment station of a textile mill in Wuqing District of Tianjin (China). The MBR-NF process showed a much better treatment efficiency on the removal of the chemical oxygen demand, total organic carbon, color and turbidity in comparison with the conventional processes. The water recovery rate was enhanced to over $90 \%$ through the recycling of NF concentrate to the MBR, while the MBR-NF showed a stable permeate water quality that met with standards and could be directly discharged or further reused. The recycled NF concentrate caused an accumulation of refractory compounds in the MBR, which significantly influenced the treatment efficiency of the MBR. However, the sludge characteristics showed that the activated sludge activity was not obviously inhibited. The results of fluorescence spectra and molecular weight distribution indicated that those recalcitrant pollutants were mostly protein-like substances and a small amount of humic acid-like substances (650-6,000 Da), which contributed to membrane fouling of NF.

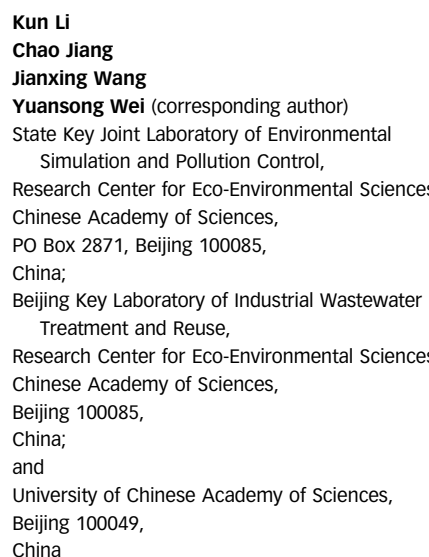

Although the penetrated protein-like substances caused the residual color in NF permeate, the MBRNF process was suitable for the advanced treatment and reclamation of textile wastewater under high water yield.

Key words | high water recovery, membrane bioreactor, nanofiltration, textile wastewater, water reclamation

\section{INTRODUCTION}

It is known that the textile industry generates a large amount of wastewater with high color and salinity, and the textile wastewater is not easy to meet the strict discharge standards by the conventional treatment processes. As the water conservation and wastewater reclamation gradually becomes a hot issue of major concern while more strict legislation is being imposed on effluent discharge, i.e., the textile wastewater is listed as the ten major industrial wastewaters according to the Action Plan for Water Pollution Prevention and Control of China issued in April 2015, more effective processes are required to deal with non-readily biodegradable pollutants in the industrial effluents (Martínez-Huitle \& Brillas 2009). The membrane bioreactor-nanofiltration (MBR-NF) process, as a double membrane system combined with aerobic activated sludge process, has been used in municipal wastewater treatment to achieve discharge standard or water reuse (Chon et al. 20I2b; Kappel et al. 2013), but few studies were focused on the reclamation of industrial wastewater (Grilli et al. 20II; Andrade et al. 20I4; Wang et al. 20I5). Meanwhile, the MBR-NF process could provide a more stable treatment performance with a more compact system and a smaller footprint than the conventional process configurations. Despite these advantages, however, the need for proper methods to deal with the NF concentrate and the membrane fouling conditions is still hindering the wider application of the membrane technology (Thamaraiselvan \& Noel 20I4). The recycling of NF concentrate to the MBR could enhance the water recovery rate of the MBR-NF system while only a very small percentage of NF concentrate was discharged or further treated, which significantly reduced the treatment cost (Wang et al. 20I5). Thus, the MBR-NF process treating textile 
wastewater at high water recovery rate could be an effective method for the advanced treatment and the reclamation of textile wastewater. The objectives of this study were to investigate the influence of the recycling of NF concentrate on the performance of MBR-NF combined process in textile wastewater treatment under high water recovery rate, as well as the color removal and the fate of organic matters through the treatment process under high NF concentrate backflow ratios.

\section{MATERIALS AND METHODS}

\section{Wastewater characteristics}

A schematic of the pilot-scale MBR-NF combined process used in this study is shown in Figure 1. The feed water of the pilot-scale MBR-NF system was the effluent of the anaerobic tank from the wastewater treatment station of a textile mill in Wuqing District of Tianjin (China). The concentrations of chemical oxygen demand (COD), total organic carbon (TOC), suspended solids (SS), turbidity and color, $\mathrm{pH}$ in the feed water of MBR-NF system were $507.97 \pm 176.22 \mathrm{mg} / \mathrm{L}, \quad 152.41 \pm 54.08 \mathrm{mg} / \mathrm{L}, \quad 335.75 \pm$ $34.56 \mathrm{mg} / \mathrm{L}, \quad 62.72 \pm 29.21$ NTU, $1378.9 \pm 405.5$ Hazen units (HUs), $8.57 \pm 0.44$, respectively. The conventional processes used in the wastewater treatment station consist of anaerobic tanks, aerobic tanks, coagulation, decolorization and sedimentation. The concentrations of COD, TOC, SS, turbidity and color in the effluent of the conventional process were $33.54 \pm 13.44 \mathrm{mg} / \mathrm{L}, 9.87 \pm 6.70 \mathrm{mg} / \mathrm{L}, 26.75 \pm$ $17.21 \mathrm{mg} / \mathrm{L}, 9.37 \pm 16.69 \mathrm{NTU}$ and $154.9 \pm 100.0 \mathrm{HUs}$, respectively.

\section{The pilot MBR-NF system}

The submerged MBR incorporated a membrane module with 40 pieces of flat-sheet membrane $(0.1 \mu \mathrm{m}$ pore size at $40 \times 0.25 \mathrm{~m}^{2}$, polyvinylidene fluoride, SINAP-25, SINAP Membrane S\&T Co., Shanghai, China), and the effective working volume of bioreactor is $1.5 \mathrm{~m}^{3}$. The MBR effluent was drawn via a peristaltic pump (Baoding Longer Precision Pump Co., USA; model BT600-2J; pump head YZ1515X) at an $8 \mathrm{~min}$ period with $6 \mathrm{~min}$ on and $2 \mathrm{~min}$ off controlled by a timer. The transmembrane pressure (TMP) and $\mathrm{pH}$ were continuously monitored and recorded twice daily. The NF unit (Anhui PLUM Membrane Technology Co., China) consisted of three spiral wound NF membrane modules with two centrifugal pumps (Grundfos, Denmark). Nanofiltration membranes from Dow-Filmtec (Filmtec ${ }^{\mathrm{TM}}$ NF90-2540, Dow, USA) were used on the basis of our former studies (Wang et al. 20I4, 20I5), and the membrane characteristics have been provided in the aforementioned literature. The NF membranes were cleaned by a $1 \mathrm{~mol} / \mathrm{L} \mathrm{NaOH}$ solution followed by a $1 \mathrm{~mol} / \mathrm{L} \mathrm{HCl}$ solution before use to remove the pollutants on membrane surface, then soaked in deionized water for 24 hours and prepressed under 12 bar for 2 hours by deionized water to ensure a steady structure

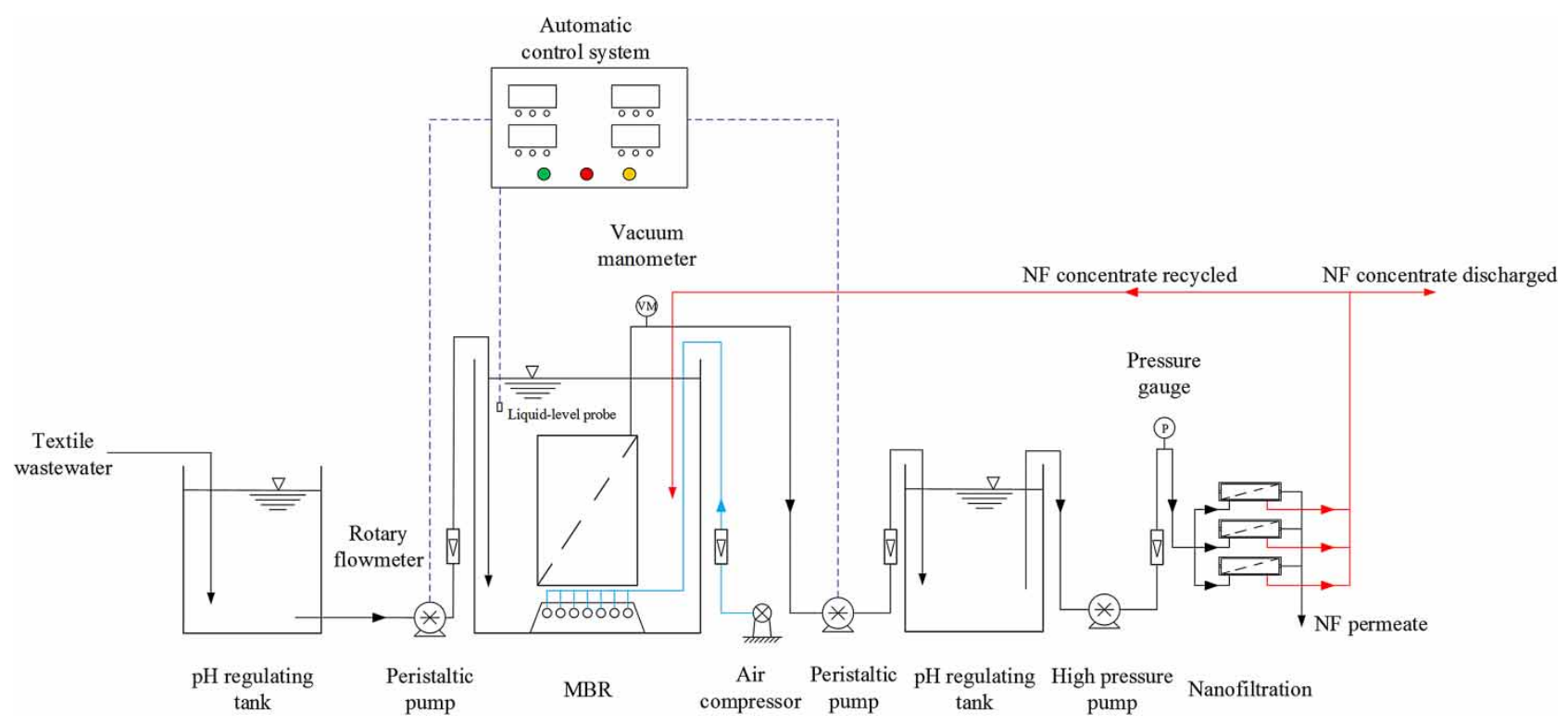

Figure 1 | Schematic diagram of the MBR-NF process. 
before each experiment. The $\mathrm{pH}$ of the textile wastewater was adjusted by $1 \mathrm{~mol} / \mathrm{L} \mathrm{HCl}$ solution to $6.5-7.5$ before being fed to the MBR continuously, and the effluent of MBR was pumped into the NF unit through a $5 \mu \mathrm{m}$ mesh filter. Two membrane modules were used in parallel combination during the experiment to provide a steady permeate flux. The NF concentrate was partly recycled to the MBR to enhance the water recovery rate and the degradation rate of the refractory compounds in textile wastewater, while the NF permeate was used as the cooling water for the NF system and miscellaneous water.

\section{Experimental conditions}

The MBR and the NF were combined and operated in continuous mode. The hydraulic retention time (HRT) of MBR was adjusted to 15 hours while the solid retention time (SRT) was maintained at 20 days (Table 1). To get a higher water recovery and a higher removal rate of pollutants, the
NF concentrate was partly recycled to the MBR and the water recovery rate was set at $80 \%$ and $90 \%$, respectively (Table 2), and the NF concentrate was pumped into the feed tank and thoroughly mixed before recycling.

\section{Analytical methods}

The concentration of COD was measured by a DR2800 spectrophotometer (HACH, USA). TOC was determined by a TOC-VCPH analyzer (Shimadzu, Japan). $\mathrm{UV}_{254}$ was measured by an ultraviolet and visible spectrophotometer (Spectrum Lab 752sp, Lengquang Tech, China). A turbidity meter (Turb 550, WTW, Germany) was used to measure turbidity. A fluorescence spectrophotometer (F-7000, Hitachi, Japan) and a gel permeation chromatography-UV detection (GPC) with a high-performance liquid chromatography system (Breeze 1525, Waters Co., USA) were used to investigate major components and the complexity of organic matters in water samples.

\begin{tabular}{|c|c|c|c|}
\hline Stages & I: No backflow & II: Backflow at water recovery rate of $\mathbf{8 0} \%$ & III: Backflow at water recovery rate of $\mathbf{9 0} \%$ \\
\hline Operational duration (d) & 3 & 27 & 27 \\
\hline $\mathrm{T}(\mathrm{C})$ & $20.58 \pm 0.75$ & $23.8 \pm 1.3$ & $16.6 \pm 2.1$ \\
\hline $\mathrm{pH}$ & $6.27 \pm 0.63$ & $7.80 \pm 0.37$ & $7.59 \pm 0.48$ \\
\hline $\mathrm{DO}(\mathrm{mg} / \mathrm{L})$ & $4.36 \pm 1.75$ & $3.15 \pm 3.29$ & $7.92 \pm 1.66$ \\
\hline HRT (h) & 15 & 15 & 15 \\
\hline SRT (d) & 20 & 20 & 20 \\
\hline MLSS (g/L) & $10.00 \pm 0.28$ & $8.03 \pm 1.34$ & $5.08 \pm 0.76$ \\
\hline MLVSS (g/L) & $8.79 \pm 0.82$ & $6.79 \pm 1.10$ & $4.48 \pm 0.86$ \\
\hline MLVSS/MLSS & $0.88 \pm 0.08$ & $0.85 \pm 0.07$ & $0.88 \pm 0.10$ \\
\hline F/M (kgCOD/kgVSS·d) & $0.18 \pm 0.02$ & $0.18 \pm 0.03$ & $0.21 \pm 0.04$ \\
\hline Load of ammonium $\left(\mathrm{gNH}_{4}^{+}-\mathrm{N} / \mathrm{kgVSS} \cdot \mathrm{d}\right)$ & $39.96 \pm 3.61$ & $50.22 \pm 8.23$ & $42.03 \pm 7.15$ \\
\hline
\end{tabular}

Table 2 | Operating characteristics of the NF

\begin{tabular}{lccc} 
Stages & I: No backflow & II: Backflow at water recovery rate of 80\% & III: Backflow at water recovery rate of 90\% \\
\hline Operational duration $(\mathrm{d})$ & 3 & 27 & 27 \\
$\mathrm{~T}(\mathrm{C})$ & $26.3 \pm 0.8$ & $25.6 \pm 1.1$ & $26.9 \pm 2.4$ \\
TMP (bar) & $6.4 \pm 0.3$ & $7.0 \pm 0.4$ & $8.1 \pm 0.2$ \\
Feed pH & $6.27 \pm 0.64$ & $6.35 \pm 0.52$ & $6.39 \pm 0.65$ \\
Concentrate pH & $6.45 \pm 0.80$ & $6.44 \pm 0.67$ & $6.43 \pm 0.71$ \\
Permeate pH & $5.54 \pm 0.34$ & $5.99 \pm 0.68$ & $6.21 \pm 0.58$ \\
Concentrate backflow ratio $(\%)$ & 0 & $83.57 \pm 3.37$ & $92.90 \pm 2.01$ \\
Water recovery rate $(\%)$ & $39.30 \pm 1.34$ & $80.14 \pm 3.73$ & $90.39 \pm 2.56$
\end{tabular}




\section{RESULTS AND DISCUSSION}

\section{Performance of MBR-NF under different water recovery rates}

The variations of membrane flux, NF concentrate backflow flux and TMP of the MBR are shown in Figure 2(a), while the NF permeability, TMP of NF and the water yield of the whole system are shown in Figure 2(b). The whole operational duration was divided into three stages as described in Tables 1 and 2. The TMP of MBR was stable in Stage I and two-thirds of Stage II, then a rapid increase was observed and the membranes were chemically cleaned in a cycle of 7-12 days during the rest of the operational duration. This phenomenon indicated that the recycling of NF concentrate would probably aggravate the membrane fouling in the MBR, especially at a high water recovery rate (i.e., 90\%). The water recovery rate of the system was around $40 \%$ when no NF concentrate was returned. The backflow of NF concentrate could increase the water recovery rate of the whole system, and replace part of the treatment capacity at the same time. The NF permeability showed a gradually decreasing trend with time and finally reached a relatively stable status in the second half of Stage III. Meanwhile, the operational pressure of NF gradually increased from 6.5 bar (with no backflow) to 8.4 bar (with backflow at 90\% water recovery), which indicated that the NF unit suffered a slowly accumulation of membrane fouling while ensuring stability of the permeate quality.

\section{Removal of COD and TOC}

As shown in Figure 3(a), the COD concentration of MBR influent varied from 430 to $790 \mathrm{mg} / \mathrm{L}$, and the MBR and the NF showed average COD removal rates of $62.43 \%$ and $97.39 \%$, respectively. It is noteworthy that the COD concentrations of MBR effluent and NF concentrate increased gradually with the backflow of NF concentrate, while that of the NF permeate was relatively stable under $20 \mathrm{mg} / \mathrm{L}$ which could meet the limit for reuse, i.e., $\mathrm{COD} \leq 30 \mathrm{mg} / \mathrm{L}$
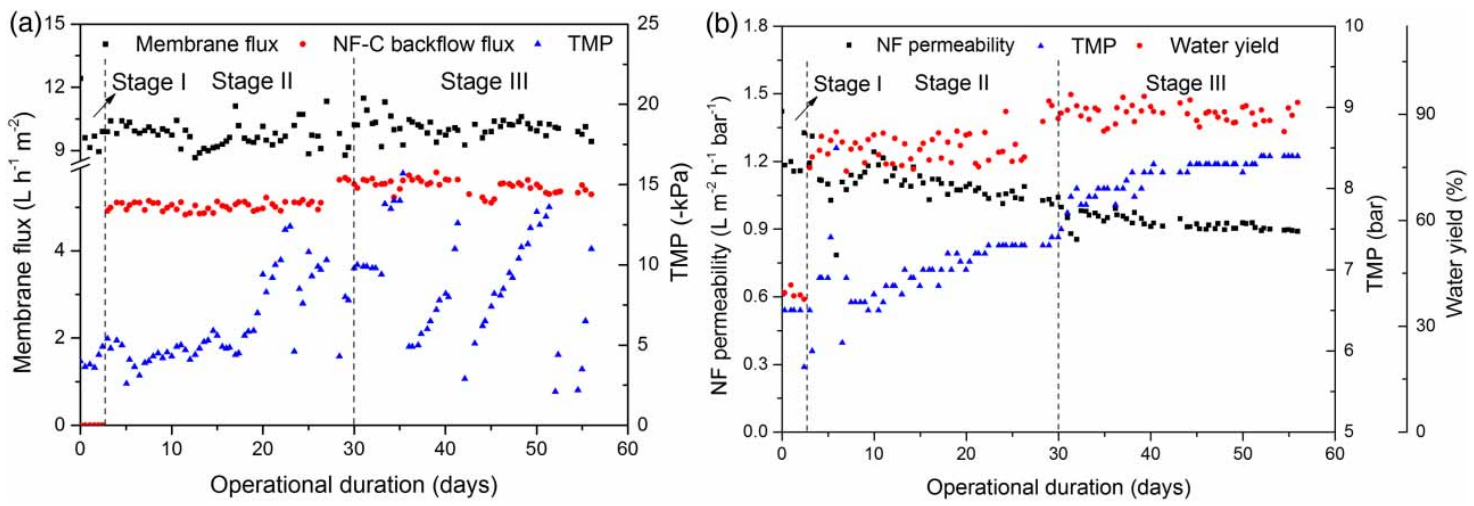

Figure 2 | Performance of the pilot MBR-NF system in the operational duration: (a) MBR and (b) NF (NF-C: NF concentrate).
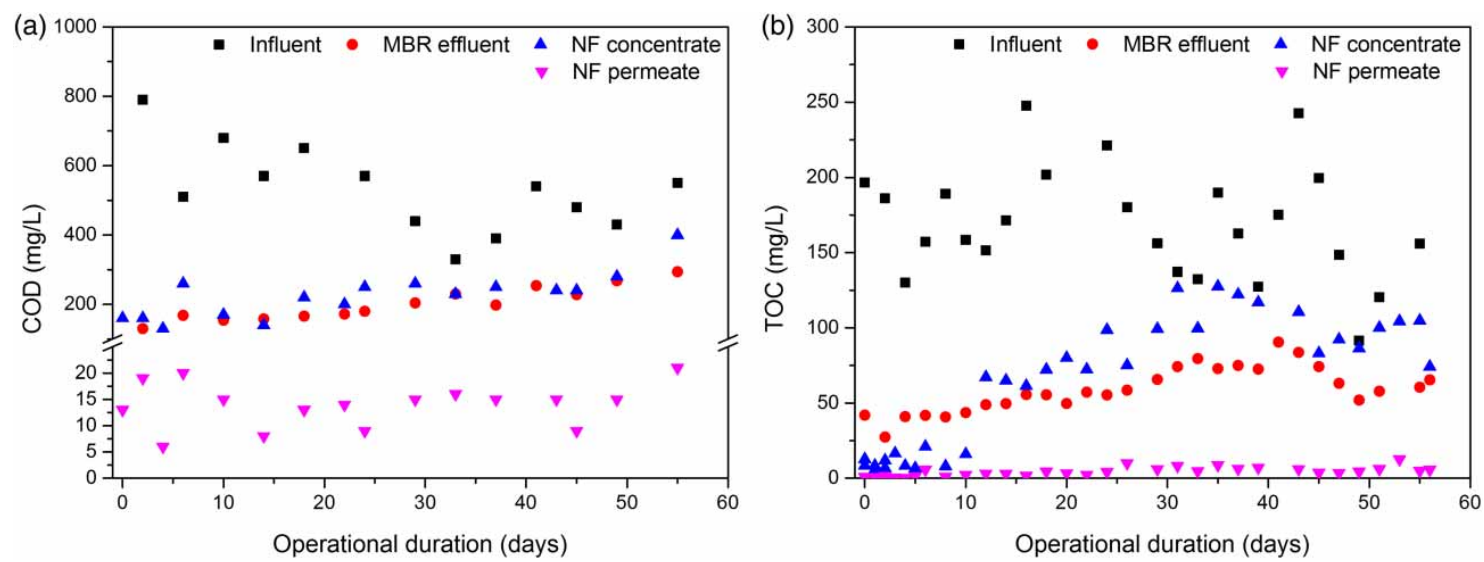

Figure 3 Variations of (a) COD and (b) TOC in the pilot MBR-NF system. 
according to 'Water quality standard for urban miscellaneous water consumption' (GB/T 18920-2002), 'Water quality standard for scenic environment use' (GB/T 18920-2002), 'Water quality standard for industrial uses' (GB/T 19923-2005) and 'Quality of farmland Irrigation water' (GB20922-2007). However, the COD of the effluent from the conventional processes showed an average value at $33.54 \pm 13.44 \mathrm{mg} / \mathrm{L}$ which could barely satisfy the requirements of those standards. Similar trends were observed from the perspective of TOC, the TOC of the MBR effluent showed an obvious increase from $34.3 \mathrm{mg} / \mathrm{L}$ to a maximum of $90.5 \mathrm{mg} / \mathrm{L}$ and then decreased to $65.4 \mathrm{mg} / \mathrm{L}$, while NF permeate was relatively stable with an average value at $3.99 \pm 3.06 \mathrm{mg} / \mathrm{L}$ of TOC which was much lower than the effluent TOC of the conventional processes at $9.87 \pm 6.70 \mathrm{mg} / \mathrm{L}$. These results indicated that the backflow of NF concentrate resulted in a significant influence on the performance of the MBR, however, its impact on the performance of the NF unit was negligible. It was reasonable to conclude that the MBR-NF process contributed to an excellent and reliable performance in textile wastewater treatment under high water recovery.

\section{Removal of color and turbidity}

The color of influent varied from 900 to $1,900 \mathrm{HU}$, while the color of the MBR effluent and the NF permeate was $563.2 \pm$ $230.3 \mathrm{HU}$ and $47.6 \pm 15.3 \mathrm{HU}$ on average, respectively, which suggested a removal rate of $44.01 \%$ and $96.41 \%$, respectively (Figure 4(a)). The color in the MBR effluent and the NF concentrate increased gradually because the organic matters with chromophores were mostly rejected by NF and were difficult to be biodegraded by the MBR. The effluent of the conventional processes showed a much higher residual color with an average value at $154.9 \pm 100.0 \mathrm{HU}$, which indicated an unstable treatment efficiency on the color removal. Both the MBR and the NF showed excellent performance on the turbidity removal, the average removal rates of turbidity by the MBR and NF were 98.86\% and 99.64\%, respectively. Similar to the removal efficiency of color, the turbidity removal by the conventional processes was much worse than that of the MBR-NF process. The turbidity in the effluent of conventional processes was $9.37 \pm 16.69$ NTU, while the turbidity of NF permeate was only $0.22 \pm 0.12$ NTU because of the great advantages brought by NF membranes. Both the color and turbidity of NF permeate meet the requirements of 'Reusing water for textile dyeing and finishing' (FZ/T 01107-2011).

\section{Sludge activity under different water recovery rates}

As shown in Figure 5, both the mixed liquor suspended solids (MLSS, mg/L) and mixed liquor volatile suspended solids (MLVSS, mg/L) concentrations decreased with the increase of the amount of NF concentrate recycling to the MBR, while both of them became relatively stable in Stage III. Combined with data shown in Table 1, the ratio of MLVSS/MLSS varied between 0.85 and 0.88 while the $\mathrm{F} / \mathrm{M}$ varied between 0.18 and $0.21 \mathrm{kgCOD} / \mathrm{kgVSS} \cdot \mathrm{d}$, which implied that the values of MLVSS/MLSS and the F/M did not change significantly throughout all the three stages of operation. Based on the results mentioned above, it was suggested that although the NF concentrate had caused a significant decrease of the sludge concentration in the MBR, it did not cause much influence on the sludge activity.

\section{Fate of organic pollutants}

The three-dimensional fluorescence excitation-emission matrix spectra (3D-EEMs) of organic matters during the
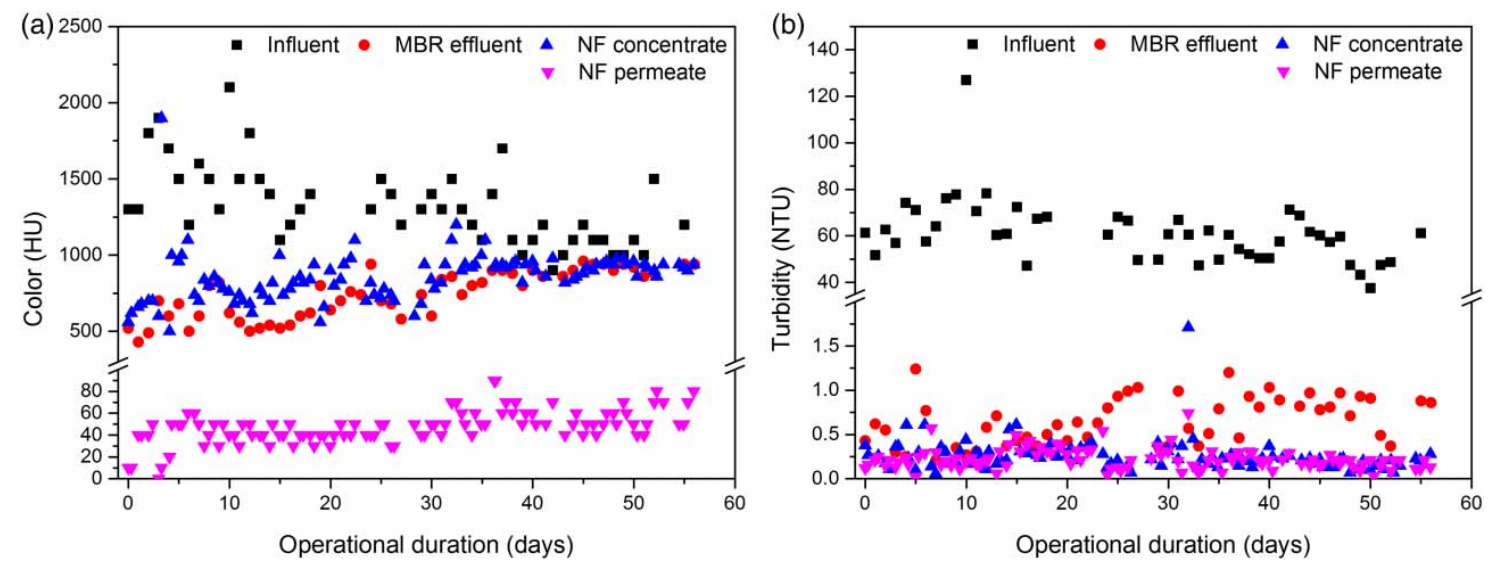

Figure 4 | Variations of (a) color and (b) turbidity in the pilot MBR-NF system. 


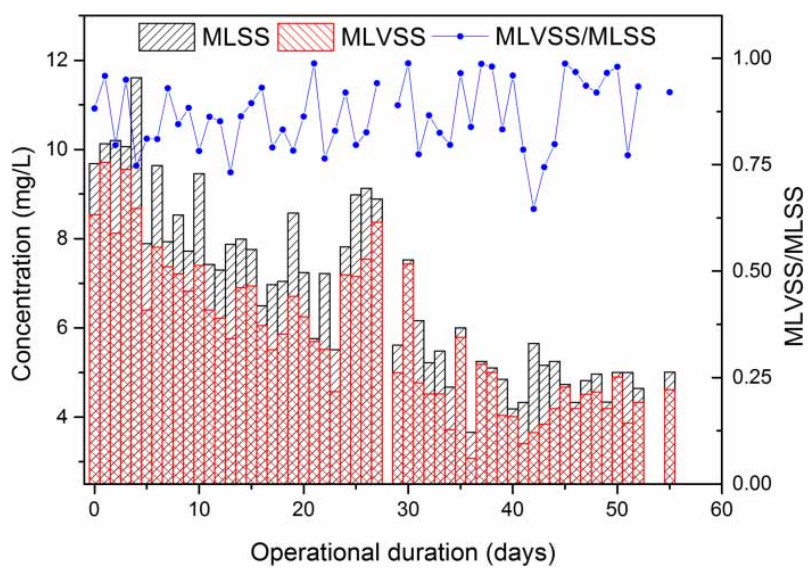

Figure $\mathbf{5}$ | The activated sludge activity under different water recovery rates.

MBR-NF treating textile wastewater is shown in Figure 6. The distribution of the peaks was divided into five regions as mentioned elsewhere (Chen et al. 2003). Four primary peaks, i.e., Peak A: $\mathrm{Ex} / \mathrm{Em}=278 / 343$ nm; Peak B: $234 / 343$ nm; Peak C: $254 / 447 \mathrm{~nm}$; and Peak D: $273 / 412 \mathrm{~nm}$, were found in the influent. The MBR showed an excellent removal efficacy in protein-like and humic acid-like substances when no NF concentrate was recycled, and intensities of all four peaks were significantly reduced in the MBR effluent, and the protein-like substances were the major pollutant residues. Then after treatment by the following NF unit, only a small amount of proteins could penetrate into the NF permeate while most organic matters were accumulated in the retentate according to the fluorescence spectra. With the increasing amount of NF concentrate recycled into the MBR, it was noteworthy that the peak intensities were correspondingly enhanced. This trend was further enhanced when the backflow ratio of NF concentrate increased from $80 \%$ to $90 \%$. These results indicated that the NF concentrate resulted in an accumulation of refractory compounds in the MBR effluent especially the protein-like substances (Peaks A and B), but the sludge activity was not affected much as aforesaid. Surprisingly, the peak intensities in NF concentrate samples from Stage II and Stage III were significantly lower than that from Stage I, which suggested that all the humic acid-like substances (Peaks C and D) and most protein-like substances (Peaks A and B) rejected by NF deposited onto the membrane surfaces or penetrated into the pores and caused the gradually increasing trend of TMP. Furthermore, the peak intensities in NF

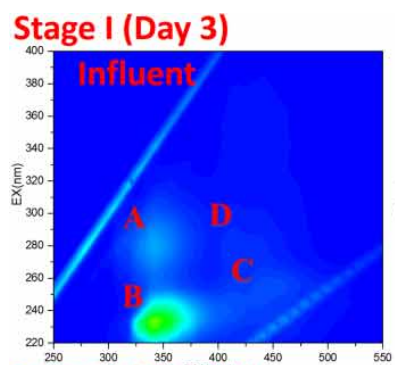

Stage II (Day $\left.{ }^{250}{ }^{250} 30\right)$

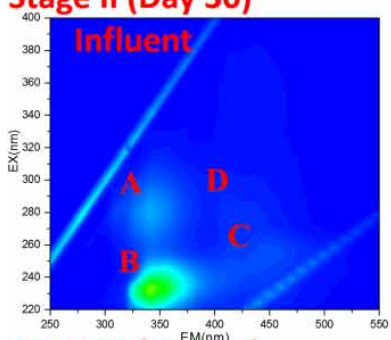

Stage III (Day 57)

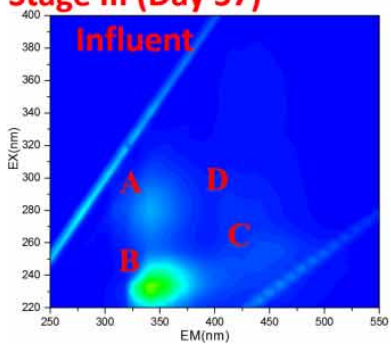

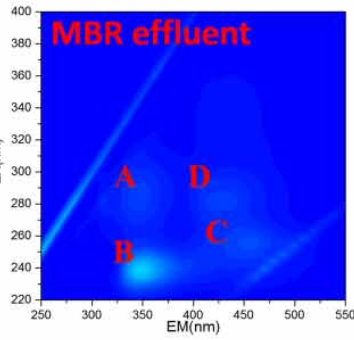
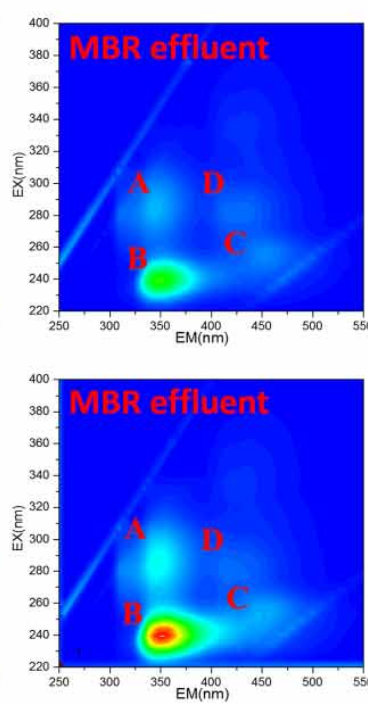
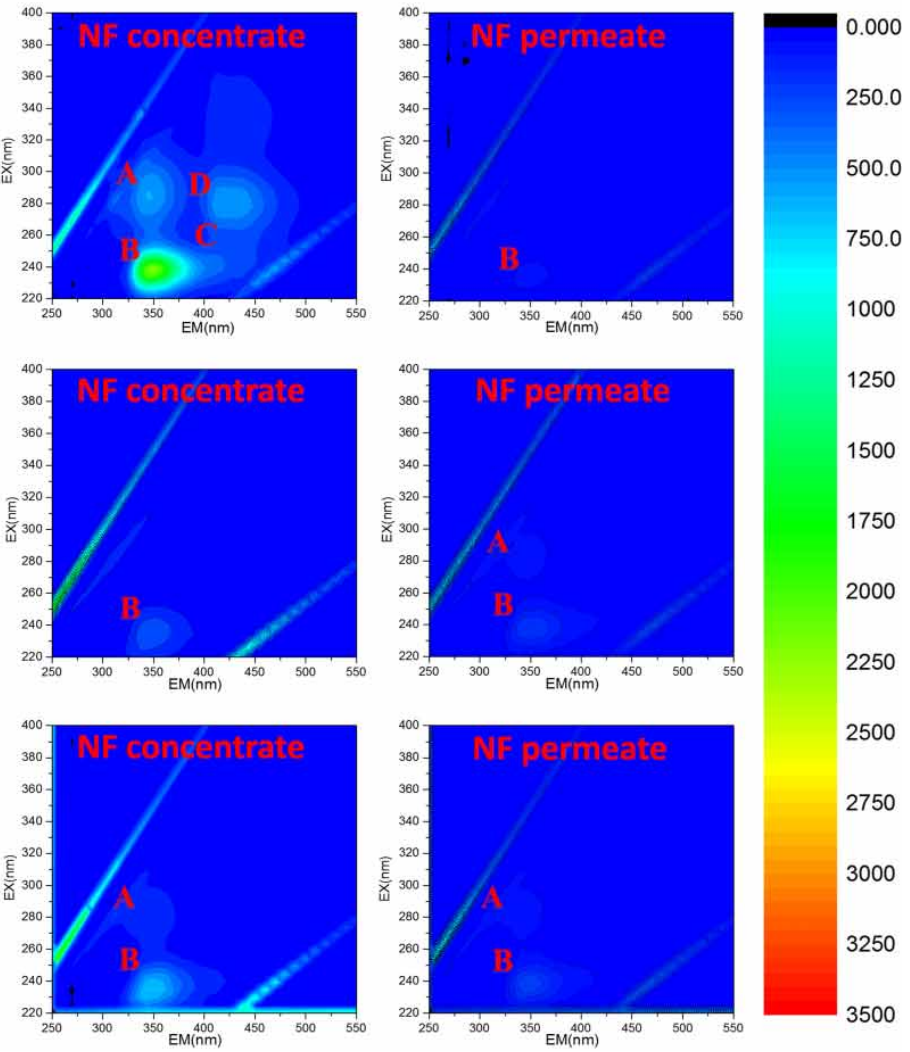

Figure 6 | 3D-EEMs of organic pollutants in wastewater samples from the pilot MBR-NF combined process. A: Tryptophan and protein-like substances related to the biological process; B: Protein-like substances; C: Hydrophobic acid, fulvic acid; D: Marine humic acids, humic acid-like substances. 
permeate grew stronger which implied that the protein-like substances were probably the primary pollutants contributing to the membrane fouling conditions.

Figure 7 shows the molecular weight (MW) distribution of organic matters in wastewater samples. The MBR effluent showed the highest peak intensities of MW distribution in the range from $650 \mathrm{Da}$ to 6,000 $\mathrm{Da}$ among all samples and the peak intensities increased with the increase of the NF concentrate backflow ratio. However no significant variations in the same range were found in both NF concentrate and permeate. These results indicated that those refractory organics brought by NF concentrate would inevitably accumulate in the MBR and influence the treatment efficiency of the MBR as shown in Figure 3, while the relatively high MW substances rejected by NF would probably deposit on the NF membrane and cause severe membrane fouling or be biodegraded into low MW substances in the range from $650 \mathrm{Da}$ to $6,000 \mathrm{Da}$ by the MBR. Furthermore, the highest peak intensities in the range from 450 Da to 650 Da were found in the NF concentrate samples while no significant variations were found in the MBR effluent accordingly, which implied that organics in that range could be well biodegraded by the MBR. Combined with the results in 3D-EEM analysis, it was reasonable to presume that organics distributed from 650 Da to 6,000 Da were mostly protein-like substances and a small amount of humic acid-like substances, while organics from $450 \mathrm{Da}$ to $650 \mathrm{Da}$ were almost all protein-like substances (Her et al. 2007; Chon et al. 2012a). Although the returning of NF concentrate had caused the accumulation of both the protein-like substances and humic-like substances in the MBR effluent, the water quality of NF permeate showed only a slightly increase of protein-like substances while no humic-like substances were found, which indicated that the MBR-NF could provide a stable performance in textile wastewater treatment and the residual color may be related to the protein-like substances. This needs further study.

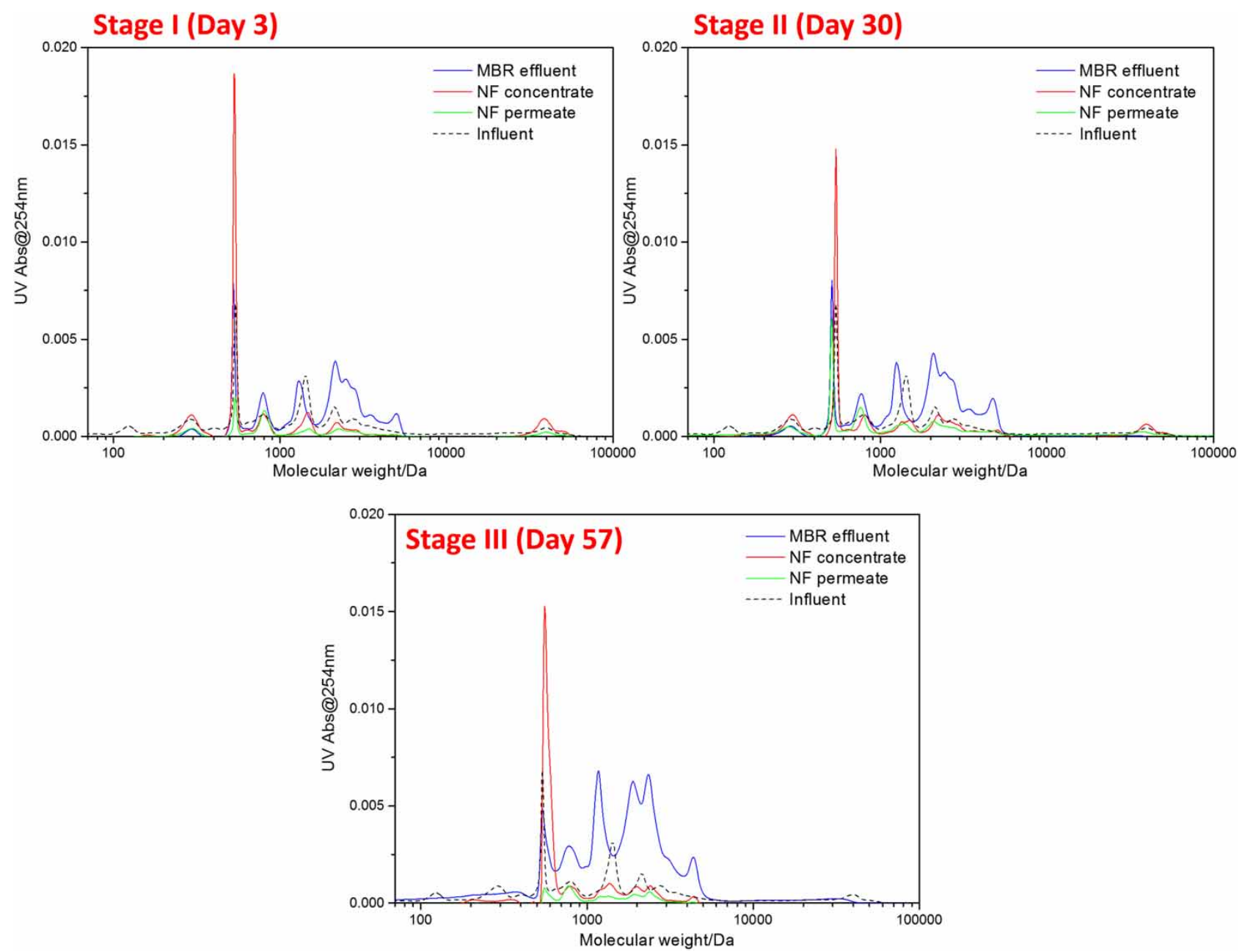

Figure 7 | Molecular weight (MW) distribution of organic pollutants in wastewater samples from the pilot MBR-NF combined process. 


\section{CONCLUSIONS}

A pilot-scale MBR-NF combined process was used for the advanced treatment of textile wastewater under high water recovery rate in this study. The results showed that the MBRNF combined process could provide much better treatment performance on the removal of the COD, TOC, color and turbidity in comparison with the conventional processes, i.e., concentrations of average COD, TOC, color and turbidity in the NF permeate were $<20 \mathrm{mg} / \mathrm{L}, 3.99 \pm 3.06 \mathrm{mg} / \mathrm{L}, 47.6 \pm$ $15.3 \mathrm{HU}$ and $0.22 \pm 0.12 \mathrm{NTU}$, respectively, which was much lower than those of effluent in the conventional processes with values of $33.54 \pm 13.44 \mathrm{mg} / \mathrm{L}, 9.87 \pm 6.70 \mathrm{mg} / \mathrm{L}$, $154.9 \pm 100.0 \mathrm{HU}$ and $9.37 \pm 16.69$ NTU. The NF permeate water quality was stable under high water yield $(>90 \%)$ and could be discharged directly or further reused. The backflow of NF concentrate to the MBR significantly influenced the treatment efficiency of the MBR because of the accumulation of refractory compounds in the MBR, however, the sludge activity was not obviously inhibited. Furthermore, those recalcitrant organic matters with MW distributed from $650 \mathrm{Da}$ to 6,000 $\mathrm{Da}$ were mostly protein-like substances and a small amount of humic acid-like substances, and they were the primary contributors for the membrane fouling in the NF unit. The residual protein-like substances in the NF permeate could be strongly related to the remaining color. It could be concluded that the MBR-NF process showed a bright future in the application of textile wastewater treatment and reclamation because of the high removal efficiency and stable performance under high water recovery rate.

\section{ACKNOWLEDGEMENTS}

Financial support provided by the National Major Science \& Technology Projects for Water Pollution Control and Management of China (No. 2012ZX07203-002; 2015ZX07203-005) and the Major Breakthrough Projects of Chinese Academy of Sciences (No. ZDTP20140201001) is gratefully acknowledged.

\section{REFERENCES}

Andrade, L. H., Mendes, F. D. S., Espindola, J. C. \& Amaral, M. C. S. 2014 Nanofiltration as tertiary treatment for the reuse of dairy wastewater treated by membrane bioreactor. Separation and Purification Technology 126 (0), 21-29.

Chen, W., Westerhoff, P., Leenheer, J. A. \& Booksh, K. 2003 Fluorescence excitation-emission matrix regional integration to quantify spectra for dissolved organic matter. Environmental Science \& Technology 37 (24), 5701-5710.

Chon, K., Cho, J., Shon, H. K. \& Chon, K. 20I2a Advanced characterization of organic foulants of ultrafiltration and reverse osmosis from water reclamation. Desalination 301, $59-66$.

Chon, K., KyongShon, H. \& Cho, J. 2oı2b Membrane bioreactor and nanofiltration hybrid system for reclamation of municipal wastewater: removal of nutrients, organic matter and micropollutants. Bioresource Technology 122, 181-188.

Grilli, S., Piscitelli, D., Mattioli, D., Casu, S. \& Spagni, A. 20 II Textile wastewater treatment in a bench-scale anaerobicbiofilm anoxic-aerobic membrane bioreactor combined with nanofiltration. Journal of Environmental Science and Health, Part A 46 (13), 1512-1518.

Her, N., Amy, G., Plottu-Pecheux, A. \& Yoon, Y. 2007 Identification of nanofiltration membrane foulants. Water Research 41 (17), 3936-3947.

Kappel, C., Yasadi, K., Temmink, H., Metz, S. J., Kemperman, A. J. B., Nijmeijer, K., Zwijnenburg, A., Witkamp, G. J. \& Rijnaarts, H. H. M. 2013 Electrochemical phosphate recovery from nanofiltration concentrates. Separation and Purification Technology 120, 437-444.

Martínez-Huitle, C. A. \& Brillas, E. 2009 Decontamination of wastewaters containing synthetic organic dyes by electrochemical methods: a general review. Applied Catalysis B: Environmental 87 (3-4), 105-145.

Thamaraiselvan, C. \& Noel, M. 20I4 Membrane processes for dye wastewater treatment: recent progress in fouling control. Critical Reviews in Environmental Science and Technology 45 (10), 1007-1040.

Wang, J. X., Wei, Y. S., Li, K., Cheng, Y. T., Li, M. Y. \& Xu, J. G. 20I4 Fate of organic pollutants in a pilot-scale membrane bioreactor-nanofiltration membrane system at high water yield in antibiotic wastewater treatment. Water Science and Technology 69 (4), 876-881.

Wang, J. X., Li, K., Wei, Y. S., Cheng, Y. T., Wei, D. B. \& Li, M. Y. 2015 Performance and fate of organics in a pilot MBR-NF for treating antibiotic production wastewater with recycling NF concentrate. Chemosphere 121, 92-100. 